\title{
A Dialogue Concerning the Nose Raymond Federman
}

P-You have ... you have ... Sir ... heuh! A very big nose.

F-Very big, you say.

$\mathrm{P}$-Yes, quite big. Enormous in fact.

F-That's all? That's all you can say?

$\mathrm{P}-\mathrm{BIG}$... very BIG!

F-Ah, my dear P, no, you must do better than that, didn't you learn anything in the Workshop? You could have said so many things, in so many different styles, so many different tones of voice. For instance:

Aggressive: Me, Sir, if I had such a nose I would have it amputated on the spot.

Friendly: It must dip into your cup when you drink, you should perhaps drink out of a plate.

Descriptive: It's a rock! It's a mountain peak! It's a volcano! What am I saying. It's a peninsula.

Curious: What use do you make of this oblong capsule? Do you use it as a writing table or a cigar box?

Gracious:You must love birds very much to offer so paternally to their little feet such a perch.

Truculent:Tell me Professor F, when you smoke and the vapors come out of your nostrils, do your students shout Fire! Fire!?

Considerate: Be careful not to lean forward too much, the weight of this thing might make you fall to the ground.

Tender: Why don't you have a little umbrella made for it so that it doesn't get burned by the sun?

Pedantic: The beast which Aristophanes called hippocampelephantocamelos must have had on his forehead as much flesh and that much bone.

Cavalier: What! This type of hook is now in style to hang one's hat on. How convenient.

Emphatic: There is no wind, no storm strong enough to make such a nose sneeze or catch a cold, except perhaps a tornado.

Dramatic: It's the Red Sea when it bleeds.

Admirative: What a great publicity sign this nose would make for a perfumer.

Lyrical: Is it a boat? When does it sail?

Naive: This monument, when is it open for public visitation?

(Freely adapted by Raymond Federman from Cyrano de Bergerac) 